\title{
Locally and Remotely Forced Subtropical AMOC Variability: A Matter of Time Scales
}

\author{
Quentin JAMET, ${ }^{\mathrm{a}}$ William K. DeWAR, ${ }^{\mathrm{a}, \mathrm{b}}$ Nicolas Wienders,${ }^{\mathrm{b}}$ Bruno Deremble, ${ }^{\mathrm{c}}$ \\ SALLy Close, ${ }^{\mathrm{d}}$ AND THIERRY PENDUfF ${ }^{\mathrm{a}}$ \\ ${ }^{\text {a } U n i v . ~ G r e n o b l e ~ A l p e s, ~ C N R S, ~ I R D, ~ G r e n o b l e ~ I N P, ~ I G E, ~ G r e n o b l e, ~ F r a n c e ~}$ \\ ${ }^{\mathrm{b}}$ Department of Earth, Ocean, and Atmospheric Science, Florida State University, Tallahassee, Florida \\ ${ }^{\mathrm{c}}$ Laboratoire de Météorologie Dynamique, Paris, France \\ d Laboratoire d'Océanographie Physique et Spatiale, Univ. de Bretagne Occidentale, Brest, France
}

(Manuscript received 14 November 2019, in final form 19 March 2020)

\begin{abstract}
Mechanisms driving the North Atlantic meridional overturning circulation (AMOC) variability at low frequency are of central interest for accurate climate predictions. Although the subpolar gyre region has been identified as a preferred place for generating climate time-scale signals, their southward propagation remains under consideration, complicating the interpretation of the observed time series provided by the Rapid Climate Change-Meridional Overturning Circulation and Heatflux Array-Western Boundary Time Series (RAPID-MOCHA-WBTS) program. In this study, we aim at disentangling the respective contribution of the local atmospheric forcing from signals of remote origin for the subtropical low-frequency AMOC variability. We analyze for this a set of four ensembles of a regional $\left(20^{\circ} \mathrm{S}-55^{\circ} \mathrm{N}\right)$, eddy-resolving $\left(1 / 12^{\circ}\right)$ North Atlantic oceanic configuration, where surface forcing and open boundary conditions are alternatively permuted from fully varying (realistic) to yearly repeating signals. Their analysis reveals the predominance of local, atmospherically forced signal at interannual time scales (2-10 years), whereas signals imposed by the boundaries are responsible for the decadal (10-30 years) part of the spectrum. Due to this marked time-scale separation, we show that, although the intergyre region exhibits peculiarities, most of the subtropical AMOC variability can be understood as a linear superposition of these two signals. Finally, we find that the decadal-scale, boundary-forced AMOC variability has both northern and southern origins, although the former dominates over the latter, including at the site of the RAPID array $\left(26.5^{\circ} \mathrm{N}\right)$.
\end{abstract}

\section{Introduction}

The Atlantic meridional overturning circulation (AMOC) plays a central role in climate by redistributing heat, freshwater, and carbon. Its strength is correlated with climate indices such as the Atlantic multidecadal variability (AMV; Kushnir 1994; Schlesinger and Ramankutty 1994; Kerr 2000) (Knight et al. 2005; McCarthy et al. 2015b), as well as to the occurrence of regional weather events. Examples are precipitation over Europe (Sutton and Dong 2012) and North Africa (Zhang and Delworth 2006) and hurricane activity in North America (Goldenberg et al. 2001; Hallam et al. 2019). Thus, understanding the mechanisms pacing AMOC variability at climate time scales is of central interest for climate predictions. Decadal AMOC variability is often argued to be paced by the North Atlantic subpolar gyre due to the longer time scales involved in its dynamics (Wunsch and Heimbach

Corresponding author: Quentin Jamet, quentin.jamet@univgrenoble-alpes.fr
2013; Menary et al. 2016; Zhang 2017). But subpolarsubtropical AMOC connectivity remains an open question, with potentially complex interactions between the deep western boundary current (DWBC) and the upper Gulf Stream. Placing the focus on the subtropical gyre where continuous measurements of the AMOC have been carried out since 2004 by the Rapid Climate Change-Meridional Overturning Circulation and Heatflux Array-Western Boundary Time Series (RAPID-MOCHA-WBTS) program (McCarthy et al. 2015a), we wish to further categorize the low-frequency AMOC variability of this region as locally or remotely paced.

A prevailing concern regarding mechanisms driving the low-frequency AMOC variability in the subtropical gyre is associated with the southward propagation of density anomalies from the subpolar gyre. While the subtropical gyre is dominated by interannual AMOC variability, the subpolar gyre is dominated by decadal time-scale dynamics (Balmaseda et al. 2007; Wunsch 2013; Wunsch and Heimbach 2013), such as deep water 
formation rates or the longer time it takes for baroclinic Rossby waves to cross the basin at higher latitudes (Wunsch and Heimbach 2013). This makes the subpolar gyre a preferred region for the generation of decadal time scale signals. Of particular importance is the southward propagation of dense water masses, which are expected to propagate to the subtropical gyre through the DWBC. As nicely reviewed by Biastoch et al. (2008a), mechanisms involved in the southward propagation of signals within the DWBC include a rapid exit of newly generated deep water masses out of the subpolar gyre and a fast equatorward communication through coastal Kelvin waves (Kawase 1987; Johnson and Marshall 2002; Deshayes and Frankignoul 2005; Hodson and Sutton 2012). Those southward traveling coastally trapped density anomalies thus lead to a zonal gradient across the North Atlantic basin, pacing an AMOC variability through geostrophic adjustment (Hirschi and Marotzke 2007; Cabanes et al. 2008; Tulloch and Marshall 2012; Buckley et al. 2012; Jamet et al. 2016).

However, recent studies cast doubt on such a simple southward pathway of density anomalies from the subpolar to the subtropical gyre. Observations do not reveal a straightforward connection between deep water masses production at high latitude and their export farther south (Schott et al. 2004; Lozier 2010). Both observational (Bower et al. 2009) and numerical (Zou and Lozier 2016) float experiments suggest rather that recently formed deep water masses in the Labrador Sea mainly recirculate within the subpolar gyre, and that only a small fraction transit farther south, a dynamics recently supported by the first 21 months of the Overturning in the Subpolar North Atlantic Program (OSNAP) observing system (Lozier et al. 2019). Additionally, a few studies have highlighted the complex dynamics involved in the southward propagation of the DWBC when crossing the upper, northward flowing Gulf Stream, with strong vertical interactions (Spall 1996a,b; Bower and Hunt 2000; Zhang and Vallis 2007; Andres et al. 2016).

Regarding southern interactions, Biastoch et al. (2008b) highlighted the potential contribution of the Agulhas linkage for the AMOC variability in the North Atlantic subtropical gyre. Using a two-way nested global configuration with refined horizontal resolution in the Agulhas region, they show that the mesoscale dynamics of this region contributes to about $0.2 \mathrm{~Sv}\left(1 \mathrm{~Sv} \equiv 10^{6} \mathrm{~m}^{3} \mathrm{~s}^{-1}\right)$ of the AMOC decadal variability, which may well contribute to about $10 \%-$ $20 \%$ of the $\sim O(1)$ Sv low-frequency variability measured by the RAPID array (Smeed et al. 2014, 2018). Such a potential contribution of the southern Atlantic for the AMOC variability in the North Atlantic subtropical gyre has also been recently underscored by Leroux et al. (2018).

AMOC variability in the subtropical gyre also responds to the local atmospheric forcing. On short time scales (from month to years), the Ekman adjustment of the ocean to local wind stress has been proposed as the leading mechanism (Hirschi and Marotzke 2007). At longer time scales, the baroclinic shear adjustment and the gyre interaction with an irregular bathymetry dominates (Häkkinen 2001; Cabanes et al. 2008). Thus, a measure of the AMOC as provided by the RAPID array would likely be a potentially complex combination of signals of different origin. Through numerical sensitivity experiments to surface forcing, Biastoch et al. (2008a) however have shown that the variability of the maximum AMOC under realistic forcing can be understood as a linear combination of an interannual variability driven by local wind forcing, and a decadal variability driven by buoyancy forcing in the Labrador Sea. This linear superposition has also been underscored recently by Kostov et al. (2020, manuscript submitted to Nat. Geosci.) in the ECCO state estimate through adjoint sensitivity experiments to ocean surface metrics, with a leading role of zonal wind stress in the local response. This would suggest that interactions between the ocean response to the local atmospheric forcing and signals of remote origin are weak, making attribution in the real ocean easier. But these studies have also pointed out the potential sensitivity of this linear superposition to the presence of oceanic eddies. We thus propose here to further analyze this linear superposition in such an eddying regime.

To further disentangle the respective contribution of the local atmospheric forcing for the AMOC variability in the North Atlantic subtropical gyre from the signals generated in remote regions (such as North Atlantic subpolar or Agulhas regions), we analyze the model outputs of four different regional ocean model configurations that differ in their forcing at the surface and at the open boundaries. Details of these simulations are given in section 2. To explicitly resolve the oceanic mesoscale dynamics (important for many oceanic processes, and in particular involved in the evolution of water mass properties in the DWBC downstream of Grand Bank; Bower and Hunt 2000; Lozier 2010), we have performed these simulations at eddy-resolving $\left(1 / 12^{\circ}\right)$ horizontal resolution. With such a resolution, a significant fraction of the AMOC variability is expected to be intrinsic, that is, driven by processes other than the forcing and with a random phase (Hirschi et al. 2013; Grégorio et al. 2015; Leroux et al. 2018; Jamet et al. 2019b). We have thus carried out these simulations with 
an ensemble strategy. We discuss in the following the results of the ensemble mean, which reflects the oceanic response to external forcing (surface and boundaries). We first extract the leading modes of the forced AMOC variability in our four ensembles and compare their spatial pattern and their spectral content (section 3 ). We then analyze full time series to assess the assumption of linearity in the combined effect of surface and boundary forced signals, and we illustrate the benefits of our ensemble strategy to identify AMOC responses to external forcing in an eddying ocean (section 4). We discuss the intrinsic AMOC variability simulated by our different ensembles in section 5 and analyze the respective contribution of northern and southern open boundaries for driving boundary forced AMOC variability in section 6 . We summarize and discuss our results in section 7.

\section{Methods}

\section{a. Model, experiments, and processing}

We use the regional North Atlantic configuration of the Massachusetts Institute of Technology general circulation model (MITgcm; Marshall et al. 1997) described in Jamet et al. (2019b). It extends from $20^{\circ} \mathrm{S}$ to $55^{\circ} \mathrm{N}$ with a horizontal resolution of $1 / 12^{\circ}$ and 46 layers in the vertical, ranging from $6 \mathrm{~m}$ at the surface to $250 \mathrm{~m}$ at depth. Open boundary conditions are applied at the side of our domain, such that oceanic velocities $(U, V)$ and tracers $(T, S)$ are restored with a 36-min relaxation time scale toward the oceanic state derived from the 55 -yr-long $1 / 12^{\circ}$ horizontal resolution ocean-only global NEMO simulation ORCA12.L46-MJM88 (Molines et al. 2014). To ensure stability at the boundary, a sponge layer is applied to the two adjacent grid points where model variables are restored toward boundary conditions with a 1-day relaxation time scale. Although these relaxation times scales are relatively short, no adverse effects were apparent upon inspection. Open boundary conditions are applied every 5 days and linearly interpolated in between.

At the surface, the ocean model is coupled to a simple atmospheric boundary layer model [Cheap Atmospheric Mixed Layer (CheapAML); Deremble et al. 2013]. In CheapAML, atmospheric surface temperature and relative humidity respond to ocean surface structures by exchanges computed according to the COARE3 (Fairall et al. 2003) flux formula but are strongly restored toward prescribed values over land. Other variables (downward longwave and solar shortwave radiation, precipitation) are prescribed everywhere. Atmospheric reanalysis products used in CheapAML originate from the Drakkar forcing set (DFS4.4; Brodeau et al. 2010; Dussin et al. 2016), consistent with the atmospheric forcing employed in the ORCA12.L46-MJM88 global simulation used to derive the open boundary conditions.

The model is first spun up for 5 years (1958-62) from the ORCA12.L46-MJM88 initial conditions [derived from Levitus (1998) climatology] under realistic forcing. Then, all ensembles are integrated forward in time for 50 years (1963-2012) with a 12-member ensemble strategy. The 12 initial conditions have been constructed through 1-yr-long simulations under 1963 forcing initialized with 2-day-apart ocean states from January 1963 . These initial conditions are meant to reflect the spread induced by the growth of small, dynamically consistent perturbations decorrelated at seasonal time scales. This set of 12 initial conditions is used across the four different ensembles, such that initial perturbations are the same in all experiments. Further details on the configuration can be found in Jamet et al. (2019b, see the supporting information therein). We focus here our analysis on the ensemble mean statistics, which we interpret as the oceanic response to external forcing (surface and boundaries). This ensemble means are thus referred to as the forced variability in the following. The departure from this ensemble mean (i.e., the ensemble spread due to intrinsic variability) is discussed in section 5 .

To disentangle the respective contribution of open boundaries and surface forcing in driving oceanic variability within our regional North Atlantic domain, we have alternatively permuted open boundaries and surface forcing from fully varying (realistic) to yearly repeating signals. The realistic ensemble (referred to as ORAR hereafter, for open boundary conditions real and atmosphere real) uses the full spectrum of open boundary conditions and surface forcing. This ensemble represents the reference test case associated with realistic conditions, which has been used by Jamet et al. (2019b) to separate forced and intrinsic AMOC variability. Results from the three other ensembles are compared to this reference experiment. To isolate the oceanic variability that is locally forced by the interannual-to-decadal atmospheric dynamics, climatological open boundary conditions are applied to the ensemble OCAR (open boundary conditions climatologic and atmosphere real). These climatological open boundary conditions have been constructed as a climatological average for the period 1963-2012; that is, 5-day open boundary conditions are averaged across the years to provide a mean representation of the seasonal cycle. They repeat every year, such that no signals at interannual and longer time scales are imposed by the boundaries. By 
contrast, to isolate the imprint of open boundaries, yearly repeating atmospheric forcing is applied to the ensemble ORAC (open boundary conditions real and atmosphere climatologic). The yearly repeating atmospheric forcing follows a "normal" year strategy (Large and Yeager 2004). This choice emerged from the recognition that, when using CheapAML, transient atmospheric winds need to be accounted for to simulate a realistic oceanic mean state (Jamet et al. 2019a). These are absent from climatological atmospheric conditions. The period August 2003July 2004 has been selected because it minimizes the difference between the number of occurrences of the Atlantic ridge weather regime and its 1958-2012 climatological mean. We have placed the focus on the Atlantic ridge weather regime to identify a normal year since it has been shown to be the weather regime that is the most correlated to the North Atlantic subtropical sea surface height interannual variability (Barrier et al. 2013). The occurrence of this weather regime has been found to induce a northward shift of the wind stress curl, altering the Sverdrup balance and generating westward propagating Rossby waves. Such processes are of importance for the low-frequency variability of the North Atlantic large-scale circulation such as the Atlantic meridional overturning circulation (AMOC), which is closely linked to the intensity of the gyres (Zhang 2008). A fourth ensemble (OCAC; open boundary conditions climatologic and atmosphere climatologic) is run with both climatological boundary conditions and "normal" year atmospheric forcing, such that the forcing involves no frequencies longer than one year. This fourth ensemble provides us a quantitative estimate of the AMOC variability that we cannot interpret as forced by the low-frequency variability of the atmospheric forcing or the boundary conditions. Although not exhaustive, possible explanations for the presence of a low-frequency, ensemble-mean AMOC variability in this ensemble may involve the presence of a "residual" intrinsic variability due to the size of our ensemble (12 members) or the development of a forced low-frequency AMOC variability through nonlinear processes. Such questions are however out of the scope of this paper, and thus left for further studies.

Finally, two additional single simulations (with no ensemble strategy) are run with fully varying open boundary conditions only at the southern or the northern extent of the domain, while all other forcings (including the surface) are yearly repeating. These two simulations will be used in section 6 to disentangle the respective contribution of the northern and the southern boundary for generating boundary forced AMOC
TABLE 1. Summary of the simulations discussed in this study, where angle brackets $(\langle\cdot\rangle)$ indicate ensemble simulations.

\begin{tabular}{lcc}
\hline \hline \multirow{2}{*}{ Open boundary } & \multicolumn{2}{c}{ Atmosphere } \\
\cline { 2 - 3 } & Fully varying & Normal year \\
\hline Fully varying & $\langle$ ORAR $\rangle$ & $\langle$ ORAC $\rangle$ \\
Climatologic & $\langle$ OCAR $\rangle$ & $\langle$ OCAC $\rangle$ \\
Northern boundary real & & runN \\
Southern boundary real & & runS \\
\hline
\end{tabular}

variability in the subtropical gyre. Table 1 provides a summary of the simulations discussed in this study.

Our focus is placed on interannual-to-decadal AMOC variability. The model output 5-day averaged AMOC time series are thus bandpass filtered to remove large variance at subannual time scales, trends, and very long frequencies unresolved by our 50 -yr-long simulations. The filter is a combination of high- and low-pass filters, and a seasonally varying climatological mean is removed. This time filtering isolates periods between 2 and 30 years (Jamet et al. 2019b). The first and last years of simulations are discarded in the following analyses due to side effects of this time filtering.

\section{b. Mean state}

The time-mean overturning circulation (computed in depth space) simulated by our reference realistic ensemble (ORAR; Fig. 1, top-left panel) exhibits a positive cell in the 3000 upper meters, peaking at about $18 \mathrm{~Sv}$ at $34^{\circ} \mathrm{N}$ and $1200-\mathrm{m}$ depth. Below $3000 \mathrm{~m}$ the overturning streamfunction is negative and of about $4-5 \mathrm{~Sv}$ at 4000-m depth. Near the surface, we also note the presence of two shallow subtropical wind-driven cells in the upper $200 \mathrm{~m}$. Although the bottom negative cell is slightly stronger than in observations (Send et al. 2011; Frajka-Williams et al. 2011), all these features are typical of what is usually found in ocean-only (Danabasoglu et al. 2014) and climate models (Gastineau and Frankignoul 2012; Muir and Fedorov 2017). Further comparisons of the ensemble mean AMOC and the RAPID-MOCHA-WBTS observational estimates can be found in the supporting information of Jamet et al. (2019b).

The three remaining panels of Fig. 1 provide estimates of the modified mean state when forcing (surface and open boundaries) is turned to yearly repeating signals. The time-mean AMOC is reduced by about $0.1-0.2 \mathrm{~Sv}$ in most of the basin under climatological open boundary conditions, with the largest reduction observed near the AMOC time-mean maximum, that is, $34^{\circ} \mathrm{N}$ and $1200-\mathrm{m}$ depth (top-right panel). The effects of turning the atmosphere from realistic to yearly repeating forcing is, not surprisingly, most pronounced in the upper layers, 

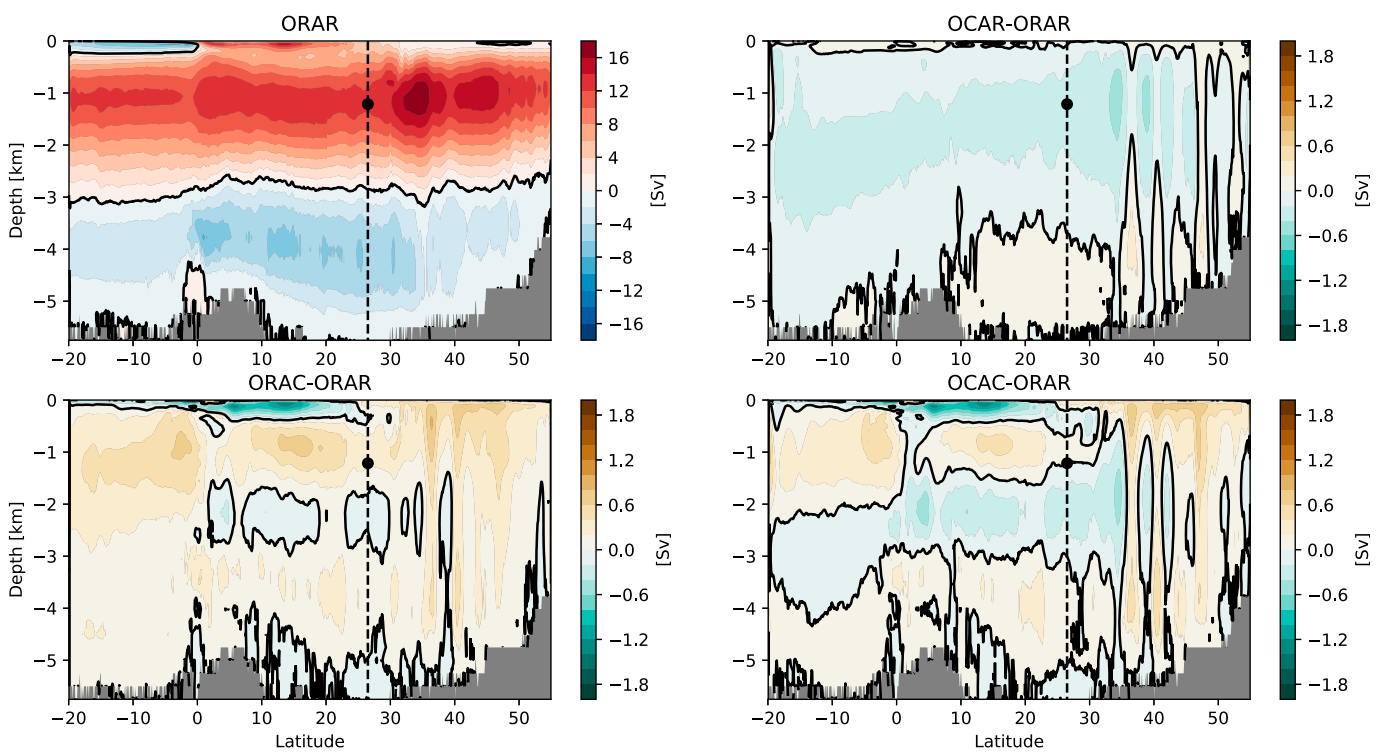

FIG. 1. (top left) Time-mean Atlantic meridional overturning circulation (AMOC) streamfunction for the reference, realistic ensemble ORAR (contour interval $=2 \mathrm{~Sv}$ ), and associated departures from this reference ensemble for the three other ensembles: (top right) OCAR, (bottom left) ORAC, and (bottom right) OCAC (contour interval $=0.2 \mathrm{~Sv})$. See Table 1 for further details on the experiments. Zero contours are in black. The dashed line represents the location of the RAPID-MOCHA-WBTS array, and the black dot is the depth of the maximum timemean AMOC used in Fig. 6. The time-mean AMOC is computed from the ensemble mean, unprocessed, 5-day averaged model outputs.

with notably a weakening of the Northern Hemisphere subtropical wind-driven cell by about $-2 \mathrm{~Sv}$ (bottomleft panel). Time-mean AMOC changes are otherwise mostly positive with local maximum $(\sim 0.5 \mathrm{~Sv})$ in localized regions. The OCAC ensemble time-mean AMOC changes illustrate the combination of these two effects (bottom-right panel). Overall, those changes remain weak in amplitude and thus lie in the range of the variety of time-mean AMOC usually simulated by models. Thus, as we will discuss below, changes in the forcing at the surface and at the boundaries primarily impact the simulated low-frequency AMOC variability, with little change in the time-mean AMOC state on which this variability develops.

\section{Leading modes of forced AMOC variability}

We extract the leading modes of forced AMOC variability in each ensemble by performing a principal component analysis (PCA) on the ensemble mean AMOC (Fig. 2). The EOF1 of the reference, realistic ensemble (ORAR; top-left panel) exhibits a broad positive signal over most of the domain, peaking to about $1.2 \mathrm{~Sv}$ at $15^{\circ} \mathrm{N}$ and $1500-\mathrm{m}$ depth, and a sign reversal around $45^{\circ} \mathrm{N}$ and $15^{\circ} \mathrm{S}$. It explains slightly less than $40 \%$ of variance, and has been interpreted, in connection with previous studies, as the AMOC response to yearly varying atmospheric forcing by Jamet et al. (2019b). This interpretation is further supported here by comparing this leading mode of AMOC variability under realistic forcing against those obtained in the other ensembles. When the interannual and longer variability of the atmosphere is removed and the surface forcing repeats every year (ORAC; bottom-left panel), the spatial pattern of the leading mode radically changes. It now exhibits a large band of meridionally coherent AMOC anomalies with no sign reversal, revealing the imprint of remotely forced signals on the subtropical AMOC variability. It reaches its maximum near the maximum of the time-mean AMOC (i.e., at $1200-\mathrm{m}$ depth). We note here that the meridional structure of this mode indicates a tendency of the AMOC to oscillate in phase at all latitudes. This would thus suggest a rapid communication of boundary signals toward the interior of the domain, potentially through Kelvin waves as suggested by others (Johnson and Marshall 2002; Biastoch et al. 2008b; Zhang 2010; Hodson and Sutton 2012; Leroux et al. 2018). In contrast, when the imprint of the low-frequency atmospheric forcing on AMOC variability is isolated from the influence of the boundaries (OCAR; top-right panel), the leading mode of variability is found to be similar to the one obtained under realistic forcing, that is, a "gyre-specific" mode with a sign reversal at the 

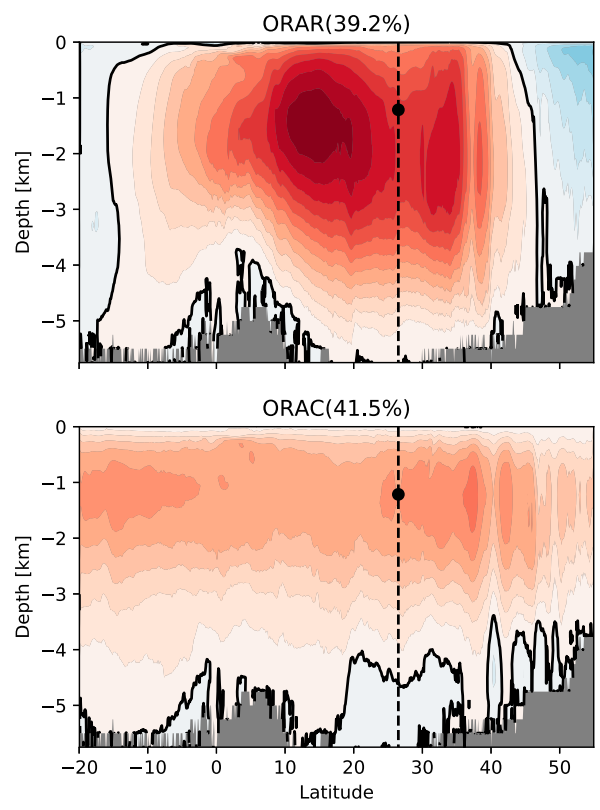

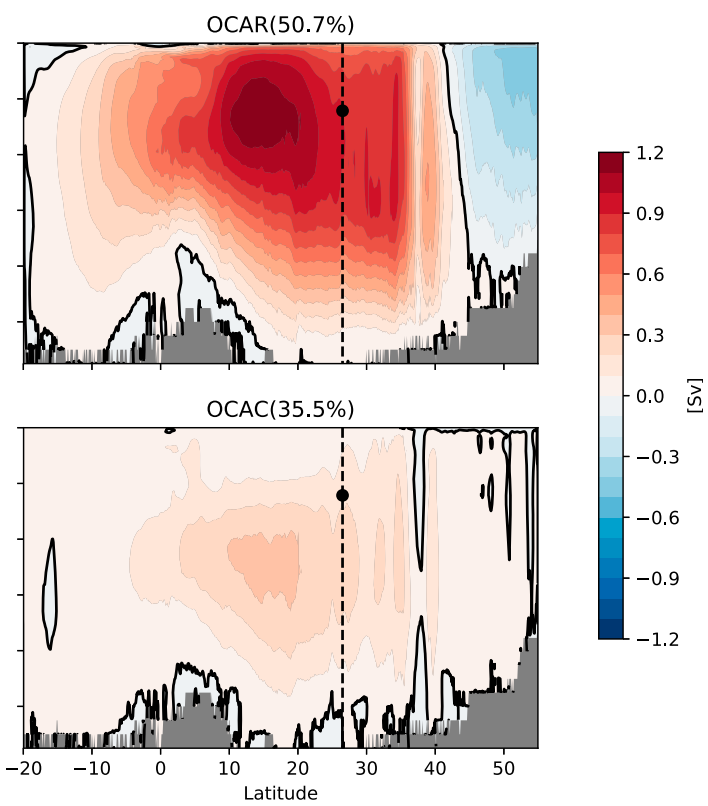

FIG. 2. Leading modes of the ensemble mean AMOC variability in the four ensembles (top left) ORAR, (top right) OCAR, (bottom left) ORAC, and (bottom right) OCAC. Empirical orthogonal functions (EOFs) have been normalized by the standard deviation of their associated principal components (PCs) such that they contain the amplitude (Sv) of the explained signal. Zero contours are in black, and the contour interval is $0.1 \mathrm{~Sv}$. The dashed line represents the location of the RAPID-MOCHA-WBTS array, and the black dot is the depth of the maximum time-mean AMOC.

intergyre. Comparing the results of these two ensembles (i.e., ORAC and OCAR) with those obtained under realistic forcing (i.e., ORAR) strongly supports earlier interpretations: The leading mode of the forced AMOC variability extracted through a PCA on a realistic simulation reflects the oceanic response to the local atmospheric forcing (Eden and Jung 2001; Eden and Willebrand 2001; Deshayes and Frankignoul 2008; Gastineau and Frankignoul 2012; Jamet et al. 2019b). Such an interpretation is also consistent with the relative magnitude of these modes. Although they all explain about $40 \%-50 \%$ of the forced AMOC variability, the leading mode in the ensemble ORAC is weaker $(\sim 0.4-0.5 \mathrm{~Sv})$ compared to those obtained under realistic atmospheric forcing $(\sim 1 \mathrm{~Sv})$. These differences are also seen in variance (Fig. 3), where the temporal standard deviation of the subtropical AMOC in the ensemble ORAC is about half of the standard deviation observed in the two ensembles driven by realistic atmospheric forcing. Thus, due to the stronger signal imprinted by the local, low-frequency atmospheric forcing on the ocean circulation, these dynamics are naturally identified as leading modes of variability through a PCA since the latter looks for modes with the largest variance. Note that we only mentioned the first EOFs here, but have also computed the second and subsequent principal components, which all exhibit more regional patterns of variability.

When both surface and open boundary forcing are yearly repeating (ensemble OCAC), a weak "residual" variability appears. The PCA of this so-called residual variability reveals that about $35 \%$ of this variability is characterized by a large-scale mode that strongly resembles the intrinsic mode of AMOC variability identified by Jamet et al. (2019b) in the realistic (ORAR) ensemble and is discussed in section 5. This suggests this mode of "forced" variability is likely to reflect a remnant of the intrinsic variability due to the relatively modest size of our ensemble size (i.e., 12 members). Although not conclusive, this supports our interpretation of a quantitative estimate of the AMOC variability that cannot be interpreted as forced by the low-frequency variability of the forcing.

Aside from their differences in spatial patterns, these modes also exhibit very distinct spectral contents. We illustrate this in Fig. 4 by reconstructing the time series of their respective maximum (i.e., multiplying the normalized PCs by the local maximum of their associated EOFs). The aim of this reconstruction is to simplify the interpretation, where spectral properties of these modes are shown with their respective amplitude. From their time series, it is clear that the leading mode of forced AMOC variability in the ensembles ORAR and OCAR 

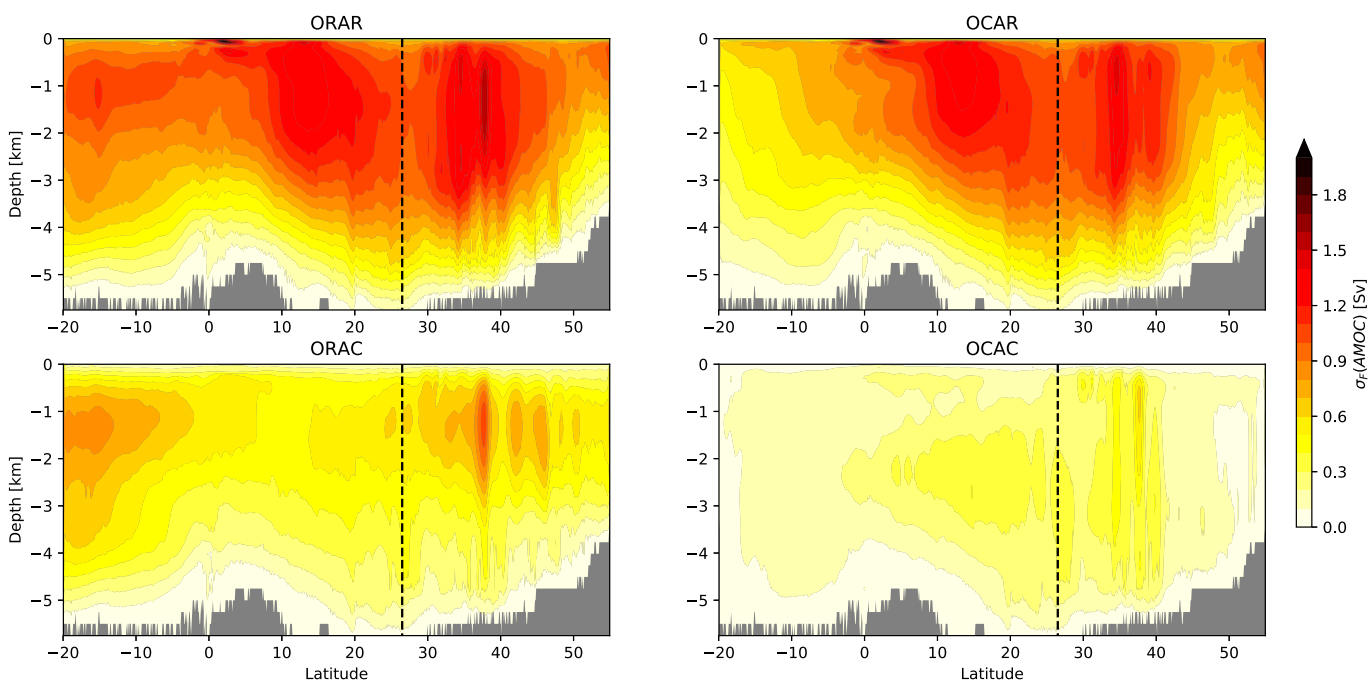

FIG. 3. Temporal standard deviation of the ensemble mean AMOC for the ensembles (top left) ORAR, (top right) OCAR, (bottom left) ORAC, and (bottom right) OCAC. The contour interval is $0.1 \mathrm{~Sv}$. The dashed line represents the location of the RAPID-MOCHA-WBTS. The temporal standard deviation is computed from the ensemble mean, time processed (band-passed filtered and deseasonalized) AMOC.

(both driven by realistic atmospheric forcing) vary almost perfectly in phase. Their respective power spectral density (PSD) functions confirm such an agreement in terms of spectral content. The agreement is particularly pronounced at interannual time scales, where both of these modes exhibit two local maxima at 2-3- and 6-8-yr frequency bands typical of the North Atlantic atmospheric spectrum (Czaja and Marshall 2001; Reintges et al. 2017). When the ocean is driven by a yearly repeating atmospheric forcing, however (ORAC and OCAC ensembles), the interannual variance strongly reduces and most of the energy resides at decadal time scales. The ensemble driven by fully varying open boundary conditions (ORAC) exhibits indeed a large peak of variability in the $10-30$-yr band, which exceeds the spectral energy of the leading mode obtained in the realistic (ORAR) ensemble. This result further supports our earlier interpretation that the leading mode of AMOC variability computed under realistic conditions reflects the response to a local, low-frequency atmospheric forcing, but contains little information about the boundary forced signal.

The PCA discussed here provides a statistical description of the main spatiotemporal patterns of AMOC variability. It however only accounts for a given fraction (about $40 \%-50 \%$ in our ensembles) of the total signal. We thus extend our spectral analysis in the following by considering full time series to further investigate
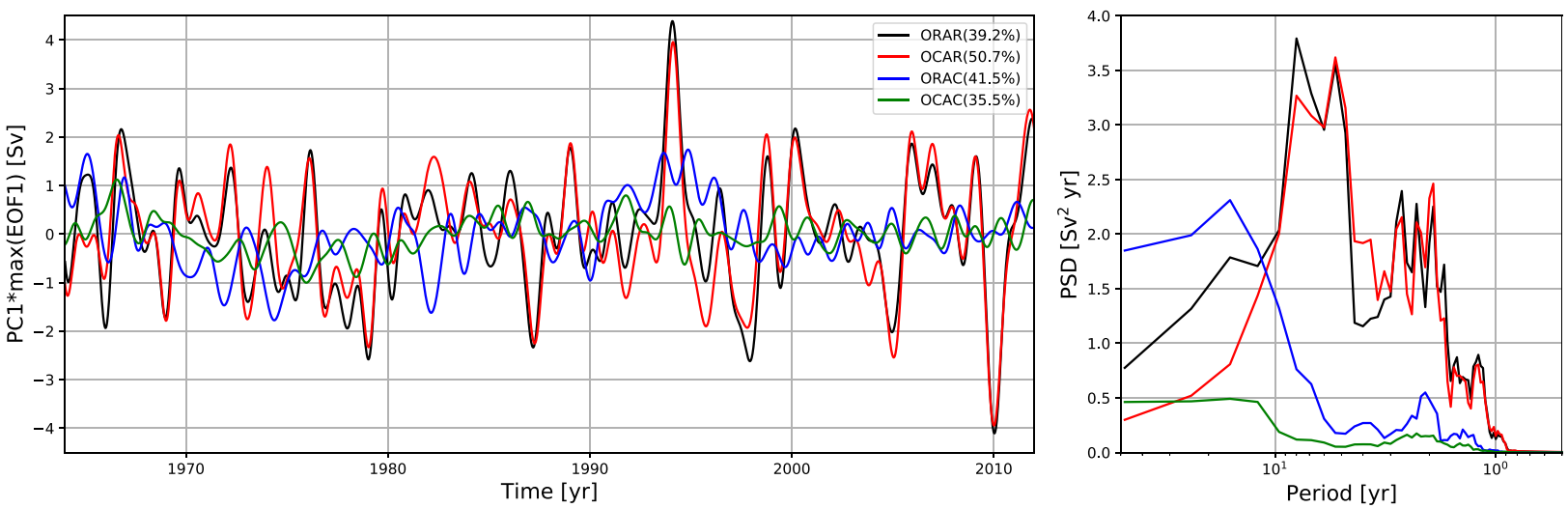

FIG. 4. (left) Time series of the PCs associated with the leading mode of variability presented on Fig. 2 and (right) their associated power spectral density (PSD) function. Normalized PCs have been multiplied by the respective maximum of their associated EOFs to account for their magnitude. 

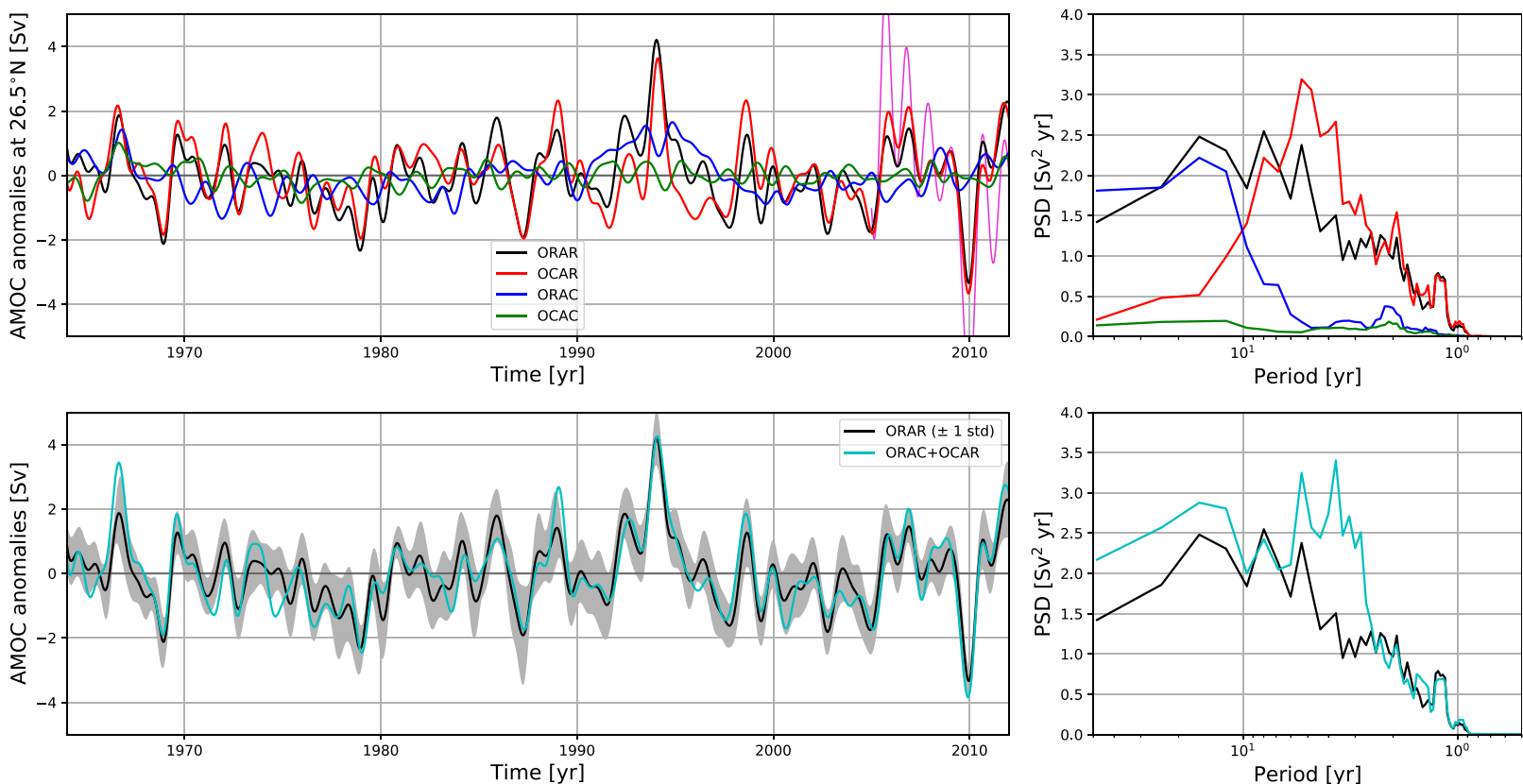

FIG. 5. (top) Time series of the ensemble mean AMOC anomalies at $26.5^{\circ} \mathrm{N}$ and $1200-\mathrm{m}$ depth in (left) the four ensembles and (right) their associated PSD functions. PSD functions have been smoothed with a 5-point moving average window. The 1-yr low-pass filtered RAPID array time series is shown in purple for comparison. (bottom) As in the top panels, but for the realistic ensemble ORAR (black), with \pm 1 standard deviation associated with the ensemble spread (gray shading) and a reconstruction made as the sum of the two ensembles' mean (ORAC + OCAR; cyan).

time-scale separation between local atmospherically forced and remotely forced AMOC variability and assess their linear combination for interpreting realistic time series.

\section{Testing the linear combination assumption}

\section{a. Analysis of full time series}

We now wish to extend our results to full time series in order to account for the complete low-frequency AMOC spectrum. To replace our numerical results in an observational context, we choose to look first at the time series simulated by our four ensembles at $26.5^{\circ} \mathrm{N}$, that is, the latitude of the RAPID-MOCHA-WBTS array (McCarthy et al. 2015a). AMOC time series at that location are plotted on the top-left panel of Fig. 5, and their associated PSDs appear on the top-right panel. ${ }^{1}$

\footnotetext{
${ }^{1}$ For comparison, the 1-yr low-pass filtered RAPID array time series is shown in purple in the top-left panel. Note however that a direct comparison with the ensemble mean AMOC time series is not possible due to the presence of intrinsic AMOC signals in the RAPID time series. These intrinsic signals have been estimated to account for about $0.9 \mathrm{~Sv}$ at RAPID site (Jamet et al. 2019b), thus contributing significantly to the mismatch between the RAPID time series and the ensemble mean AMOCs.
}

Differences in the AMOC time series of our ensembles are largest between the two ensembles driven by the full spectrum of atmospheric forcing (i.e., ORAR and OCAR), against those driven by yearly repeating atmospheric forcing (i.e., ORAC and OCAC), reflecting here again the stronger control of the local atmospheric forcing on the low-frequency AMOC variability. Thus, AMOC variability simulated by the ensemble OCAR tends to closely follow that simulated by the realistic ensemble ORAR, with most of the interannual peaks of variability consistently reproduced. We note for instance that the several Sverdrup downturn in 2009/10, which has been monitored by the RAPID array and interpreted as an atmospherically forced signal (Roberts et al. 2013; Zhao and Johns 2014; Leroux et al. 2018), is well reproduced by the two ensembles driven by fully varying atmospheric forcing, but is not in the two ensembles driven by yearly repeating atmospheric forcing. Our results are thus consistent with, and support, this earlier interpretation. We note however that the ensemble OCAR exhibits a more energetic AMOC variability in the 3-6-yr band than the realistic ensemble ORAR (top right panel). This would suggest that low-frequency atmospheric forcing drives an AMOC variability within this frequency band that is damped by the realistic open boundary forcing.

Focusing now on decadal time scales, spectral analysis reveals that the AMOC variability in the 

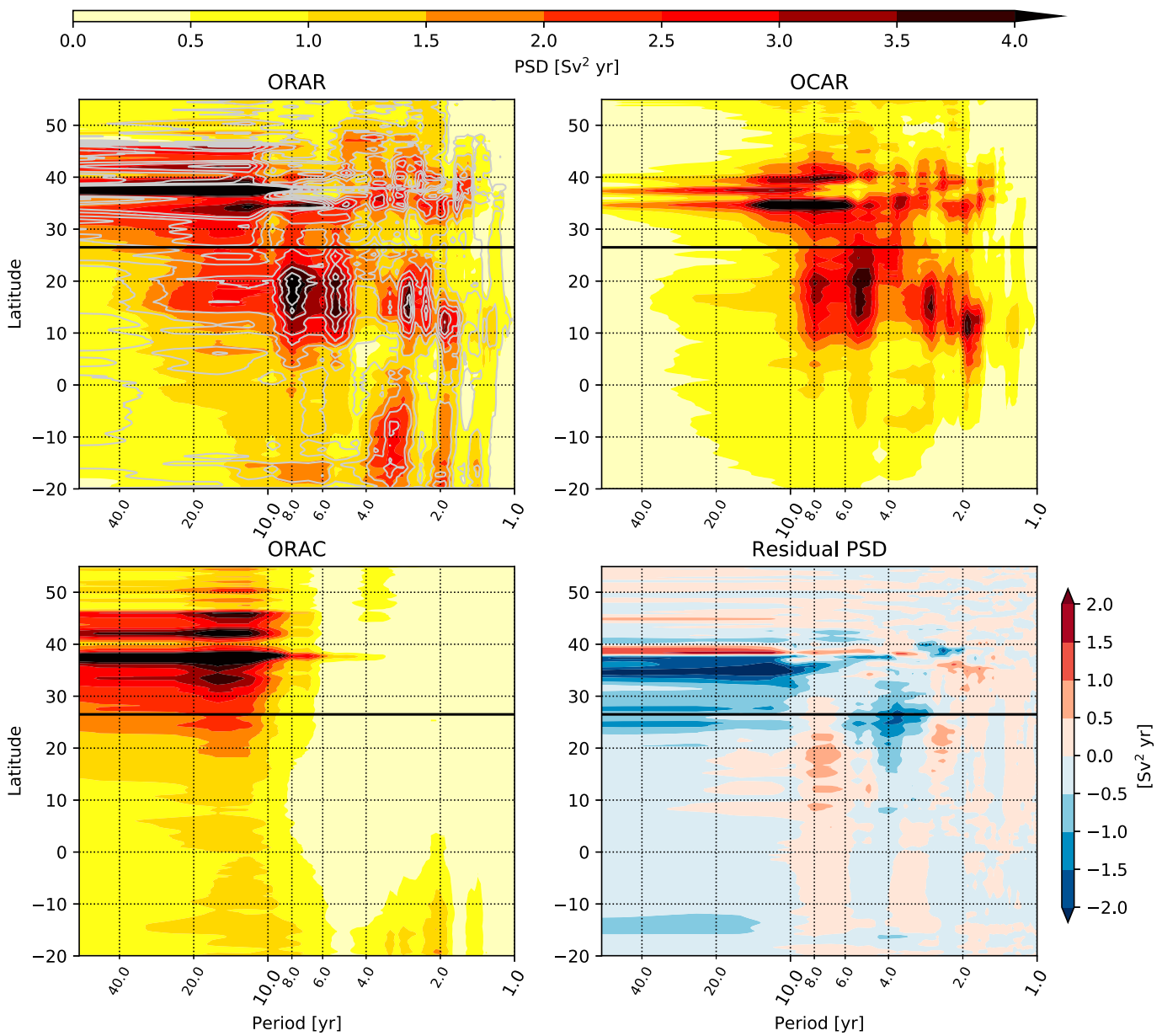

FIG. 6. Ensemble mean AMOC PSD functions as a function of latitude at 1200-m depth for the three ensembles (top left) ORAR, (top right) OCAR, and (bottom left) ORAC. Gray contours in the top-left panel show the PSD of the reconstructed AMOC as a combination of the two ensembles ORAC + OCAR. (bottom right) The error in the reconstructed spectral content. Blue colors indicate that the PSD of the reconstructed AMOC time series exceeds that of the realistic ensemble. PSD functions have been smoothed with a 5-point moving average window. The black line indicates the latitude of $26.5^{\circ} \mathrm{N}$.

ensemble OCAR is weak compared to the realistic ensemble ORAR (Fig. 5, top panels). Results from the ensemble ORAC suggest that the spectral content of the AMOC variability at those time scales is indeed driven by the open boundaries, with a spectral content consistently reproduced. These results thus suggest that the time-scale separation between the local, atmospherically forced signal and the signal driven by open boundaries identified for leading EOFs holds for the full time series of AMOC variability. As a result, it is likely that the subtropical AMOC variability could be understood as a linear superposition of these two signals. We will further test this assumption in section $4 \mathrm{~b}$.

We now wish to extend these results to all latitudes in our domain, that is, from $20^{\circ} \mathrm{S}$ to $55^{\circ} \mathrm{N}$. At 1200 -m depth, the maximum of the time-mean AMOC, we then compute at all latitudes the PSD function of AMOC time series for each ensemble mean and compare their results. Results appear in Fig. 6 for the three ensembles ORAR, OCAR, and ORAC. Results for the ensemble OCAC are not shown. Previous analyses show a very weak signal in this ensemble, and we have verified that this holds at all latitudes. Results from the ensemble ORAC confirm our earlier findings, namely that the open boundary conditions drive AMOC variability at decadal time scales. For shorter time scales, the spectral content in this ensemble is weak and does not explain any of the spectral peaks in the 1-10-yr band found in the realistic ensemble ORAR. Similarly, results from the ensemble OCAR confirm that the local atmospheric forcing drives AMOC variability at interannual time 
scales. In this frequency band, the spectral content of the realistic ensemble ORAR is consistently reproduced. However, we found that the ensemble OCAR also exhibits significant AMOC variability at decadal time scales in the $30^{\circ}-40^{\circ}$ latitude band. This would suggest that at these latitudes the atmosphere exerts a stronger effect on decadal AMOC variability. This region is characterized by the subpolar-subtropical intergyre position, suggesting a potential adjustment of the latter to decadal fluctuation in the local wind stress (Zhang 2010). At these latitudes, both remote signals and local atmospheric forcing imprint a decadal AMOC variability, with potentially complex interactions.

To conclude, although peculiarities arise at the subpolarsubtropical intergyre position $\left(30^{\circ}-40^{\circ} \mathrm{N}\right)$, spectral estimates highlight that forced AMOC variability is driven by local atmospheric forcing at interannual time scales and remote processes at decadal time scales in most of the subtropical gyre. Based on this time-scale separation, we thus suspect that in the realistic ensemble ORAR, AMOC variability can be understood as a linear combination of these two sources of variability as suggested earlier by Biastoch et al. (2008a).

\section{b. The linear assumption}

We aim here at assessing to which extent the realistic forced AMOC variability can be understood as a linear combination of local, atmospherically forced and remotely generated signals. For this purpose, we reconstruct an AMOC streamfunction as the sum of the two streamfunctions simulated by the ensembles OCAR and ORAC, and compare it with the realistic ensemble ORAR. Following the previous section, we first present and discuss results at $26.5^{\circ} \mathrm{N}$, and then extend our analysis at all latitudes of our regional domain.

At $26.5^{\circ} \mathrm{N}$ (Fig. 5 , bottom panels), results from this reconstruction are promising. The reconstructed time series is highly correlated $(r=0.9)$ to the realistic forced AMOC variability and lies within the ensemble spread induced by intrinsic ocean dynamics (gray shading). When taken separately, the forced AMOC variability in the ensemble OCAR (ORAC) is correlated to $r=0.8$ $(r=0.3)$ to the time series diagnosed in the realistic ensemble ORAR. Added together, the contribution of each ensemble dynamics is to improve correlation with realistic estimates of the forced AMOC variability, although most of the correlation is due to the atmospheric forcing, consistent with a stronger control of the latter compared to remote signals. The large strengthening of the AMOC by about $4 \mathrm{~Sv}$ in the mid-1990s provides a nice illustration for this reconstruction. Over this period, the AMOC time series in the ensemble OCAR is indeed off by about $1 \mathrm{~Sv}$ compared to the realistic ensemble
ORAR. But the ensemble ORAC exhibits at the same time a low-frequency signal that contributes to about $1 \mathrm{~Sv}$ to the strengthening of the AMOC. Added together, the reconstructed time series is in very good agreement with the AMOC variability in realistic conditions over that period.

Although the correlation between the two time series is high $(r=0.9)$, we note however that differences occur over the course of the simulation. Spectral analyses highlight that such discrepancies have preferred frequency, with a more energetic reconstructed AMOC in the 3-6-yr band and at decadal time scales (Fig. 5, bottom-right panel). The 3-6-yr band corresponds to the frequency band where the ensemble OCAR exhibits an overestimated AMOC variability compared to the realistic scenario (cf section $4 \mathrm{a}$ ). These results would suggest that in this frequency band, the AMOC variability at $26.5^{\circ} \mathrm{N}$ cannot be understood as a linear combination of two independent signals; rather, the interactions between them need to be accounted for.

We now extend the analysis of the reconstructed AMOC time series for all latitude ranges within our domain. At 1200-m depth, the spectral content of the reconstructed AMOC superimposes on the spectral content of the realistic ensemble ORAR with a good level of agreement (Fig. 6). The general patterns of the spectral content closely match, and regions of high spectral density are consistently reconstructed. This visual inspection is further supported by taking the difference of these two PSDs. Results appear on the bottom right panel of Fig. 6, where blue colors indicate a more energetic reconstructed AMOC. Although significant differences are observed at specific locations, we found that most of the AMOC variability in our realistic ensemble can be understood as a linear combination of the two ensembles OCAR and ORAC. Marked differences appear however at some localized spots, such as the decadal AMOC variability in the $30^{\circ}-40^{\circ} \mathrm{N}$ latitude band. We identified earlier this latitude band as a region where the local atmospheric forcing imprints an AMOC variability at decadal time scales. Such a surface forcing would thus potentially interact with the decadal signal imposed by the boundaries, leading to a more complex signal than a simple linear combination. We also note that the mismatch in the 3-6-yr band between the reconstructed and the realistic AMOC variability at $26.5^{\circ} \mathrm{N}$ seems to be a peculiarity of the $20^{\circ}-30^{\circ} \mathrm{N}$ latitude band.

Permuting open boundaries and surface forcing from realistic to yearly repeating signals induces an imbalance between the state of the ocean and the applied new boundary conditions. To adjust, the ocean is likely to generate wave-like signals in response to these 

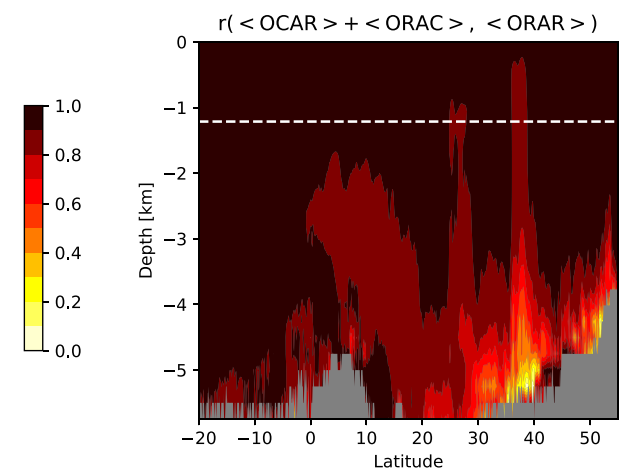
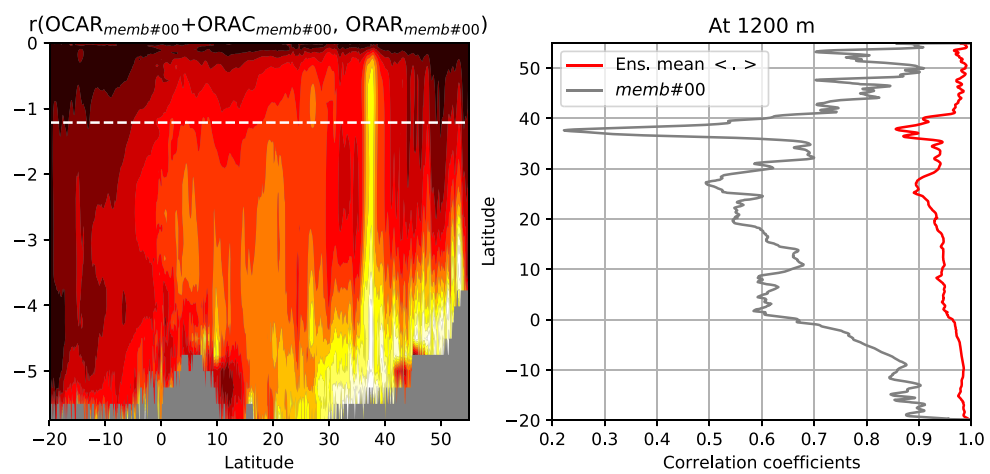

FIG. 7. Correlation coefficients between the realistic experiment ORAR and the linear reconstruction OCAR + ORAC for (left) the ensemble mean and (center) member \#00 only. (right) Correlations at the depth of $1200 \mathrm{~m}$ for the ensemble mean (red) and member \#00 only (gray).

changes, such that we cannot exclude the presence of artificial modes in our regional configuration. Such modes could imprint into the AMOC and may well play a role in the overestimated variability at $26.5^{\circ} \mathrm{N}$ and in the $30^{\circ}-40^{\circ} \mathrm{N}$ latitude band diagnosed in the ensemble OCAR. Although further analyses are required to consistently assess the potential effects of such modes, we note that our results are similar to what Leroux et al. (2018) diagnosed in their global and North Atlantic $1 / 4^{\circ}$ ensembles. When constrained by imposed climatological boundary conditions at $21^{\circ} \mathrm{S}$ and $81^{\circ} \mathrm{N}$, the two leading modes of the ensemble mean AMOC in their 10-member regional North Atlantic ensemble exhibit a slightly larger amplitude than the leading modes diagnosed in their global, 50-member ensemble. The two ensembles used by Leroux et al. (2018) are significantly different from ours, especially regarding boundary conditions, but they exhibit differences that compare well with our results. This suggests a dynamical origin of the overestimated AMOC variability in our OCAR ensemble rather than numerical artifacts.

\section{c. Benefits of the ensemble}

We have shown that the realistic AMOC variability within the North Atlantic subtropical gyre can be understood, to a good extent, as a linear superposition of signals with different origins. This supports the earlier findings of Biastoch et al. (2008a) and Kostov et al. (2020, manuscript submitted to Nat. Geosci.) and extends their results in an eddying regime. We recall that we have performed our analysis with an ensemble strategy, which we want to illustrate the benefits to identify the ocean responses to external forcing. We compare here the results of our ensemble analysis with results one could obtain with single simulations. The four ensembles have been initialized with the same set of
12 initial conditions. Comparing the members across the ensembles is thus the analog of regular sensitivity experiments conducted with single simulations (i.e., with no ensemble strategy).

We consider here the correlation between the reconstructed and the realistic AMOC variability. Results appear in the left panel of Fig. 7 for the reconstruction based on ensemble means. The reconstructed AMOC is correlated to the realistic AMOC to at least $r=0.9$ in most of the basin. These correlations weakened in the Gulf Stream region and at depth, where intrinsic AMOC variability has been shown to be the largest (Jamet et al. 2019b). When considering only one member however (Fig. 7, center panel), the correlations strongly reduce in most of the basin. At 1200-m depth (Fig. 7, right panel), correlations drop to $r=0.6$ in the subtropical gyre and to $r=0.2$ in the Gulf Stream region. These low correlations reflect the presence of an intrinsic AMOC variability, which we further discuss in section 5. This intrinsic AMOC variability imprints in all simulations with similar patterns and spectral contents, but with a random phase. These contributions do not add linearly, explaining the lower correlations obtained when considering single, eddy-resolving simulations. This result illustrates the benefits of ensemble simulations to disentangle the respective role of the forcing in eddyresolving simulations, where intrinsic ocean variability that emerges at these resolutions needs to be filtered.

\section{Intrinsic AMOC variability}

We have thus far focused on the forced AMOC variability as simulated by our four ensembles. This forced signal has been computed through an ensemble average. This averaging operation captures the signal common to all members within an ensemble, and thus reflects the ocean response to external forcing (we recall here that 
a
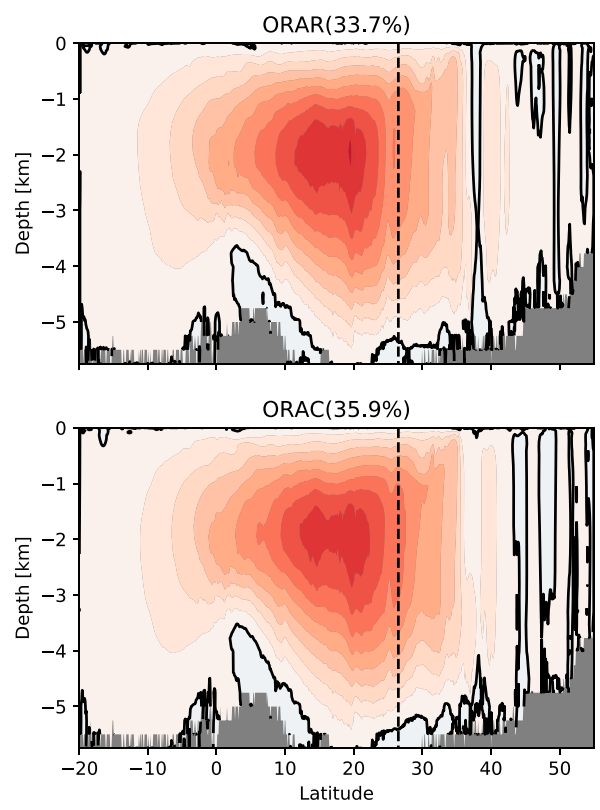

b

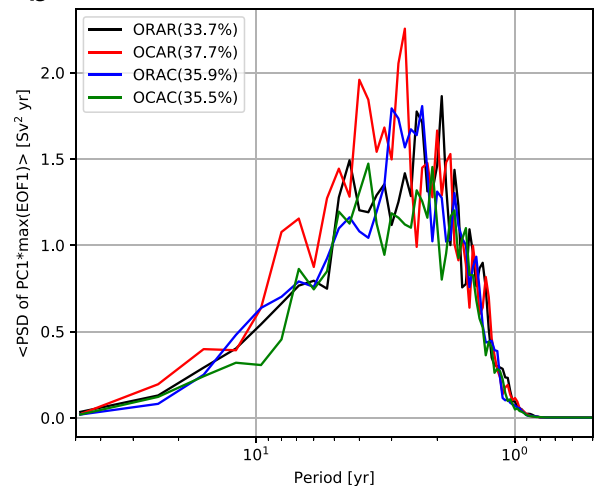

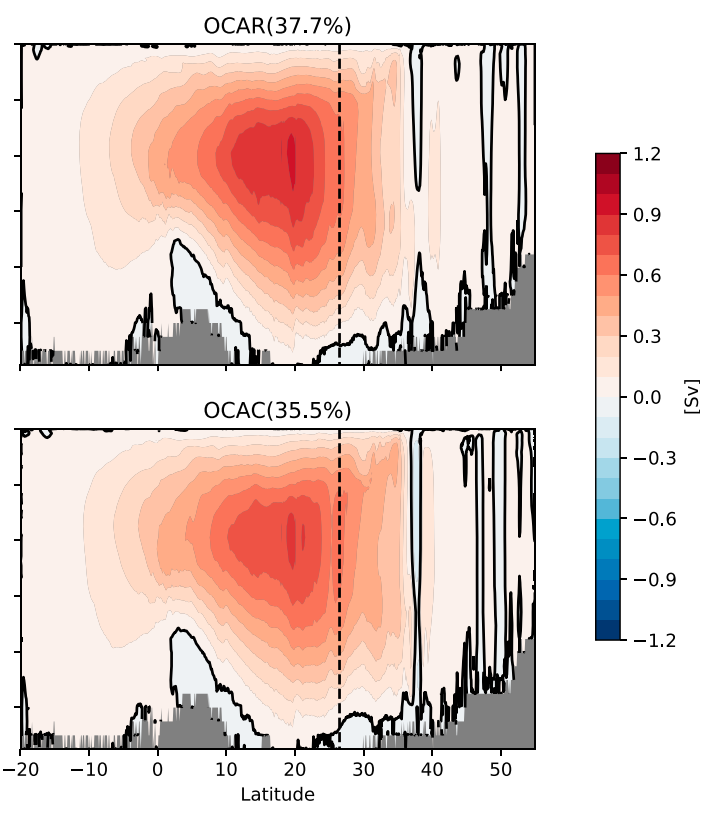

FIG. 8. (a) Leading mode of intrinsic AMOC variability for the four ensembles (top left) ORAR, (top right) OCAR, (bottom left) ORAC, and (bottom right) OCAC. EOFs have been normalized by the standard deviation of their associated PCs such that they contain the amplitude (Sv) of the explained signal. Zero contours are in black, the contour interval is $0.1 \mathrm{~Sv}$, and the dashed line represents the location of the RAPIDMOCHA-WBTS array. (b) Associated spectral content, computed as the ensemble-averaged PSD functions of the normalized PCs multiplied by the maximum of their associated EOF. all members of an ensemble are exposed to the same surface and open boundary forcing). However, each member within a given ensemble is not locked to this ensemble mean. They exhibit sensitivity to initial conditions such that a significant portion of the AMOC variability within a given member is driven by intrinsic oceanic dynamics (Hirschi et al. 2013; Grégorio et al. 2015; Leroux et al. 2018; Jamet et al. 2019b). We thus now want to focus on this intrinsic component of the variability by considering the ensemble spread in our four ensembles and assess its sensitivity to changes in the forced signal.

Following Jamet et al. (2019b), we first compute, within each of the four ensembles, the departure of each member from its associated ensemble mean. We then perform a PCA on each ensemble member residual and average the results together to yield a map of intrinsic
AMOC variability. Results of this analysis highlight the presence of a basin-scale mode of intrinsic variability in each ensemble that strongly resembles the intrinsic basin-scale mode identified by Jamet et al. (2019b) in the realistic ensemble ORAR (Fig. 8). This basin-scale mode peaks at about $1.2 \mathrm{~Sv}$ in the subtropical gyre near 2000-m depth, and mostly expresses at interannual time scales. In previous sections we have discussed the fundamentally different characteristics of the forced AMOC variability simulated by these ensembles. Thus, the level of agreement found in the intrinsic component of these ensembles highlights the very weak sensitivity of the basin-scale mode of intrinsic AMOC variability to changes in the surrounding forced component of the AMOC variability. Such a weak sensitivity has been reported earlier by Leroux et al. (2018) for the intrinsic AMOC 
variability at middepth. Our results provide a vertical and spectral generalization of this earlier finding.

\section{Northern and southern origin of the decadal AMOC variability}

Biastoch et al. (2008b) have provided evidence that decadal AMOC variability in the North Atlantic subtropical gyre might be imprinted by Agulhas mesoscale dynamics. Those results contrast with the prevailing mechanism for explaining the decadal subtropical AMOC variability as being paced by high-latitude processes such as deep water formation. Their results have recently been supported by Leroux et al. (2018) in their 50-member global ocean ensemble, where they identified a South Atlantic mode of intrinsic AMOC variability. This suggests that the mesoscale dynamics of the Agulhas Current have the potential to pace intrinsic AMOC variability farther north, and thus are likely to imprint on the RAPID observations at $26.5^{\circ} \mathrm{N}$. In our regional configuration, this South Atlantic signal would be part of our southern boundary, and would thus emerge as a forced signal. ${ }^{2} \mathrm{We}$ have derived our open boundary conditions from the $1 / 12^{\circ}$ global ocean simulation ORCA12, which is a higher-resolution version of the ORAC025 configuration used by Leroux et al. (2018) in their ensemble simulations. We are thus confident that our boundary conditions are relevant for imposing a South Atlantic mode of variability. To isolate the influence of our southern boundary from its northern counterpart, we analyze the two additional simulations, runN and runS, driven by either northern or southern fully varying boundary conditions, respectively, with the remaining forcing being yearly repeating (including surface forcing).

Due to large computational time required to generate ensembles, we were not able to produce ensembles for these additional simulations. They are thus single realizations, such that ensemble statistics are not at our disposal for accurately separating the forced AMOC variability from its intrinsic counterpart. Instead, we leverage results from our four ensembles to interpret the dynamics simulated by these two additional single simulations. We particularly recognize that those two simulations are driven with yearly repeating atmospheric

\footnotetext{
${ }^{2}$ Note that here, the forced origin of this South Atlantic dynamics on the North Atlantic subtropical AMOC variability results from our regional model strategy. It does not question the intrinsic origin of this variability in the real ocean, as proposed by others with global simulations (Biastoch et al. 2008b; Hirschi et al. 2013; Grégorio et al. 2015; Leroux et al. 2018).
}

forcing, such that interannual forced AMOC variability in the North Atlantic subtropical gyre is expected to be weak. The dynamics that develops at those time scales thus mostly reflects intrinsic ocean processes. We estimate the amplitude of this intrinsic variability by examining one member of the ensemble OCAC. This ensemble is driven by yearly repeating atmospheric forcing and open boundary conditions, providing an estimate of the signals that develop in our regional configuration at low frequency that cannot be interpreted as forced. Within this ensemble, member \#02 exhibits the strongest intrinsic variability within the subtropical gyre. We thus use this member to maximize our estimates of AMOC variability that cannot be interpreted as forced. Additionally, we previously identified that the boundary forced AMOC signals dominate at decadal time scales; therefore, we now focus our discussion in this frequency band.

AMOC anomalies at 1200-m depth are shown in Fig. 9 as latitude-time Hovmöller diagrams. Comparing AMOC anomalies in the two single simulations runN and runS with the ORAC ensemble mean strongly suggests that our decadal boundary-forced AMOC variability is mostly driven by signals entering the domain through the northern boundary. The simulation runN exhibits indeed a marked strengthening during the late 1990s very comparable to the AMOC variability diagnosed in the ORAC ensemble mean, although it is less regular in time due to the presence of interannual intrinsic variability. In contrast, no such signal is found in runS, suggesting a weaker impact of southern origin dynamics for the overall North Atlantic subtropical AMOC variability. Also note that our detrending procedure has removed very low-frequency AMOC signals (not shown). At $26.5^{\circ} \mathrm{N}$, this very low-frequency variability exhibits a strengthening of the AMOC maximum up to the mid-1990s of about $1 \mathrm{~Sv}$, and a decay afterward. This signal is observed in both the ORAC ensemble mean and in runN, consistent with what can be found in ocean models of the CORE-II experiments (Danabasoglu et al. 2016). In contrast, we did not find evidence of such a signal in runS, suggesting here again the leading role of subpolar North Atlantic dynamics for the low-frequency AMOC variability within the North Atlantic subtropical gyre.

Finally, although the imprint of the southern boundary on the forced AMOC variability is globally weak, its contribution, not surprisingly, prevails in the southern part of our regional domain. South of the equator, intrinsic AMOC variability is weak ( $\sigma=0.3 \mathrm{~Sv}$; Fig. 9, topright panel), such that AMOC anomalies observed in runS can be interpreted as driven by our southern boundary. At these latitudes, AMOC variability in runN 

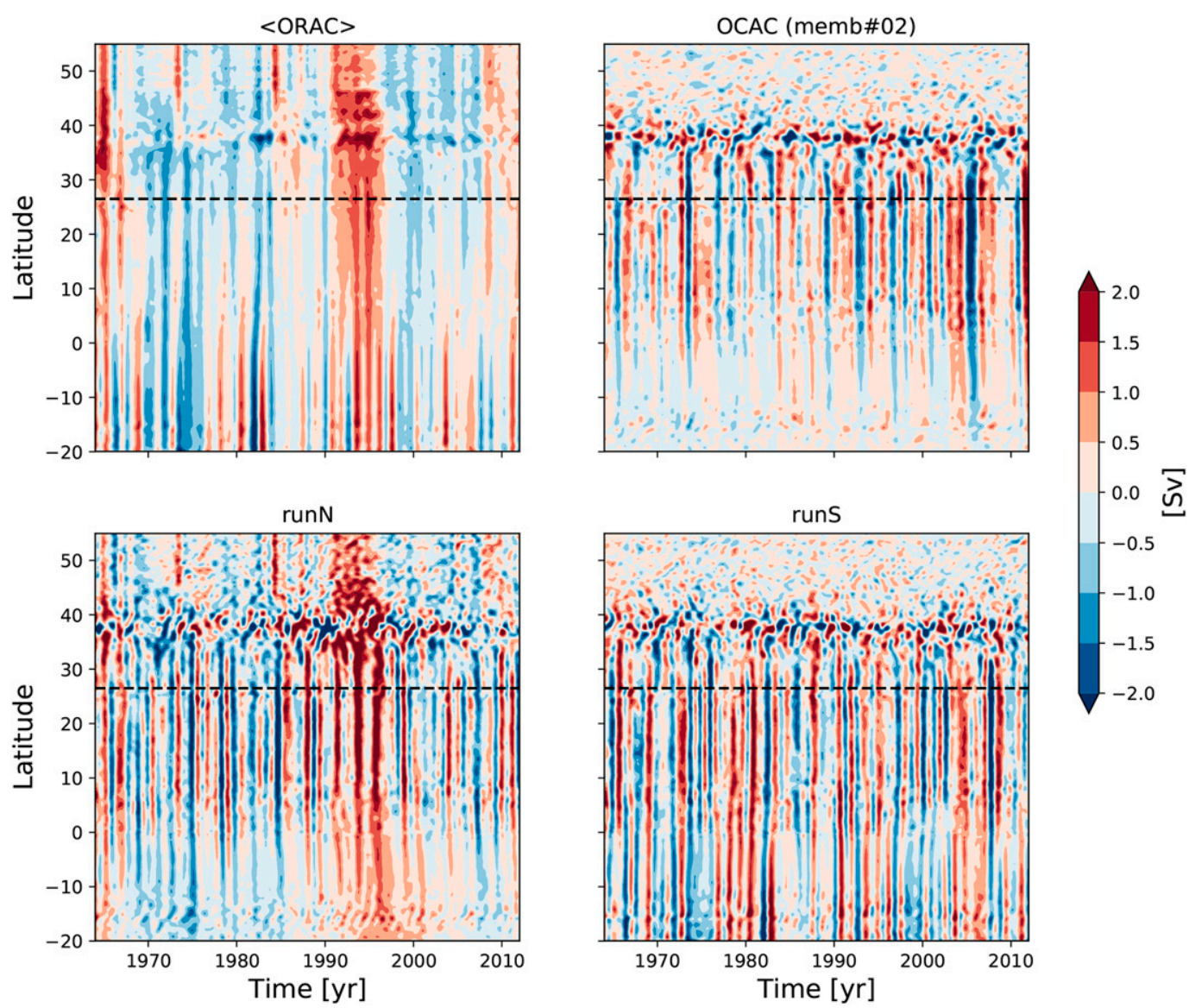

FIG. 9. Latitude-time Hovmöller diagrams of AMOC anomalies at 1200-m depth for (top left) the ORAC ensemble mean, where the angle brackets $(\langle\cdot\rangle)$ indicate ensemble averaging, (top right) ensemble member \#02 of the ensemble OCAC, and (bottom) the two additional, single simulations runN and runS. The contour interval is $0.5 \mathrm{~Sv}$. The black dashed line indicates the latitude of $26.5^{\circ} \mathrm{N}$.

is also weaker ( $\sigma=0.5$ and $\sigma=0.8 \mathrm{~Sv}$ for runN and runS, respectively), and does not explain the 0.7-Sv AMOC standard deviation diagnosed in the ORAC ensemble mean. In contrast with the northern boundary, the signal imprinted by the southern boundary contains energy at interannual time scales. This is visible in the Hovmöller diagrams of both the ensemble mean $\langle$ ORAC $\rangle$ and of runS, as well as in the spectral estimates of AMOC variability (Fig. 6, bottom-left panel). In the North Atlantic subtropical gyre, the AMOC variance is slightly larger in the runS than in OCAC ensemble member \#02 ( $\sigma=1 \mathrm{~Sv}$ and $\sigma=0.8 \mathrm{~Sv}$, respectively), suggesting a weak contribution of about $0.1-0.2 \mathrm{~Sv}$ for the overall subtropical AMOC variability. This would suggest that, although their imprints are weak, South Atlantic signals could make their way through the equator and contribute to AMOC variability farther north. Those results are consistent with earlier studies (Biastoch et al. 2008b; Leroux et al. 2018), but we are not able to robustly investigate such a northward propagation route with a single, eddy-resolving simulation. Further investigations are thus required to support those preliminary estimates of the contribution of South Atlantic dynamics for the North Atlantic subtropical AMOC variability.

\section{Summary and discussion}

We analyzed in this study the results of four ensemble simulations of a regional $\left(20^{\circ} \mathrm{S}-55^{\circ} \mathrm{N}\right)$ configuration of the North Atlantic. This analysis focused on the origin (local or remote) of the forced, low-frequency (2-30 years) variability of the Atlantic meridional overturning circulation (AMOC) in the subtropical gyre. Simulations have been carried out at eddy-resolving resolution $\left(1 / 12^{\circ}\right)$ to account for the role of eddies in the general ocean circulation. Ensemble statistics have thus been applied to isolate the AMOC signals driven by forcing from those with an intrinsic origin due to nonlinear dynamics explicitly resolved at this resolution. The four ensembles have been exposed to different forcing, 
where we have alternatively permuted surface and boundary forcing from fully varying (realistic) to yearly repeating signals. Comparing the AMOC variability simulated by these four ensembles allows us to disentangle the respective contribution of low-frequency atmospheric forcing from signals with a remote origin and entering the domain through the boundaries. The main results can be summarized as follows:

1) Isolating the variability driven by the local atmospheric forcing from the variability driven by open boundaries revealed a pronounced time-scale separation: The leading mode of AMOC variability driven by local surface forcing dominates at interannual (2-10 years) time scales, while that driven by open boundaries dominates at decadal (10-30 years) time scales. Due to the stronger imprint of the local atmospheric forcing, the leading mode of AMOC variability in realistic conditions (i.e., with both realistic surface and realistic boundary forcing) extracted through PCA mostly reflects the imprint of the atmosphere.

2) The marked time-scale separation between surface and boundary forcing allows for a good reproduction of the realistic AMOC variability in most of the subtropical gyre through a linear combination of surface and boundary forced signals. Peculiarities emerged however at the subtropical-subpolar intergyre position. There, the imprint of the atmosphere is found to extend at decadal time scales and interact with the boundary forced signal.

3) Although marked differences appeared in the forced (ensemble mean) AMOC variability, all ensembles exhibit a very similar intrinsic (ensemble spread) AMOC variability. They all reproduce a basin scale mode of intrinsic AMOC variability peaking at $20^{\circ} \mathrm{N}$ and 2000-m depth, with interannual time scales. This highlights the very weak sensitivity of this intrinsic mode to the surrounding forced AMOC variability, and thus no causal relationship between the two.

4) Both northern and southern boundaries are found to contribute to AMOC variability within our domain, although with different amplitudes. Overall, the contribution of northern origin signals dominates, particularly at the RAPID site $\left(26.5^{\circ} \mathrm{N}\right)$, but southern origin signals might well contribute at second order.

These results bring new insights in the partitioning of the subtropical AMOC variability. Although the sensitivity experiments on the southern or northern origin of the boundary-forced AMOC variability suggest a stronger imprint of the northern boundary signal for AMOC variability at $26.5^{\circ} \mathrm{N}$, they also support the earlier findings of Biastoch et al. (2008b) and Leroux et al. (2018) where the southern boundary is found to imprint a weak AMOC variability at $26.5^{\circ} \mathrm{N}$, with a likely intrinsic origin (Leroux et al. 2018). Such a contribution is suggested to be on the order of $0.1-0.2 \mathrm{~Sv}$, consistent with their earlier estimates. Dedicated studies are however required to provide a robust estimate of the imprint of the South Atlantic dynamics on the subtropical AMOC variability, thus helping the interpretation of the RAPID-MOCHA-WBTS time series. For this purpose, a filtering procedure could be developed to consistently filter intrinsic AMOC variability, such as what Close et al. (2020) proposed to separate forced and intrinsic variability of the sea surface height. Applying such a filtering procedure to the AMOC time series would first reduce the computational time required to extract forced AMOC signals from single, eddy-resolving simulations, and would also help interpreting the forced component of AMOC variability as observed by the RAPID-MOCHA-WBTS (McCarthy et al. 2015b) or the OSNAP (Lozier et al. 2017) arrays.

Finally, we would like to further discuss the implications of our results at the intergyre position. We found that the atmosphere drives AMOC variability at decadal time scales in the $30^{\circ}-40^{\circ}$ latitude band, which interacts with the decadal-scale signals driven by boundaries. As a result, the realistic $\mathrm{AMOC}$ variability in this region cannot be reconstructed through a linear combination of these two signals. These results are in line with the complex dynamics associated with the crossover of the Gulf Stream and the Deep Western Boundary Current (Spall 1996a,b; Bower and Hunt 2000; Zhang and Vallis 2007; Andres et al. 2016). From a Lagrangian point of view, however, modifications of DWBC signals through interaction with the Gulf Stream are expected to imprint farther south as those signals propagate along the western boundary. However, within the subtropical gyre, we found that the linear reconstruction leads to consistent estimates of the realistic low-frequency AMOC variability. These results thus question the role played by the complex dynamics at the intergyre position with regard to the low-frequency AMOC variability of the subtropical gyre and the interpretation of the RAPID array time series.

Acknowledgments. This work has been founded by the NSF Award OCE-1537304, and by the "Make Our Planet Great Again"' CONTaCTS project led by William K. Dewar. High-performance computing resources on Cheyenne (doi:10.5065/D6RX99HX) have been provided by NCAR's Computational and Information Systems Laboratory, sponsored by the National Science Foundation, under the university large allocations UFSU0011. We also thank Bernard Barnier from 
l'Institut des Géosciences de l'Environnement (IGE; Grenoble, France) and his collaborators for providing necessary data to force our regional model, and Stephanie Leroux from Ocean Next for fruitful discussions during the preparation of this manuscript. Data from the RAPID AMOC monitoring project are funded by the Natural Environment Research Council and are freely available from www.rapid.ac.uk/rapidmoc. The simulations used in this study are available at http:// ocean.fsu.edu/ qjamet/share/data/forced_amoc_2019/.

\section{REFERENCES}

Andres, M., J. Toole, D. Torres, W. Smethie Jr., T. Joyce, and R. Curry, 2016: Stirring by deep cyclones and the evolution of Denmark Strait overflow water observed at line W. Deep-Sea Res. I, 109, 10-26, https://doi.org/10.1016/j.dsr.2015.12.011.

Balmaseda, M. A., G. C. Smith, K. Haines, D. Anderson, T. N. Palmer, and A. Vidard, 2007: Historical reconstruction of the Atlantic meridional overturning circulation from the ECMWF operational ocean reanalysis. Geophys. Res. Lett., 34, L23615, https://doi.org/10.1029/2007GL031645.

Barrier, N., A.-M. Treguier, C. Cassou, and J. Deshayes, 2013: Impact of the winter North-Atlantic weather regimes on subtropical sea-surface height variability. Climate Dyn., 41, 1159-1171, https://doi.org/10.1007/s00382-012-1578-7.

Biastoch, A., C. W. Böning, J. Getzlaff, J.-M. Molines, and G. Madec, 2008a: Causes of interannual-decadal variability in the meridional overturning circulation of the midlatitude North Atlantic Ocean. J. Climate, 21, 6599-6615, https:// doi.org/10.1175/2008JCLI2404.1.

$\longrightarrow,-$, and J. Lutjeharms, 2008b: Agulhas leakage dynamics affects decadal variability in Atlantic overturning circulation. Nature, 456, 489-492, https://doi.org/10.1038/nature07426.

Bower, A. S., and H. D. Hunt, 2000: Lagrangian observations of the deep western boundary current in the North Atlantic Ocean. Part II: The Gulf Stream-deep western boundary current crossover. J. Phys. Oceanogr., 30, 784-804, https://doi.org/ 10.1175/1520-0485(2000)030<0784:LOOTDW >2.0.CO;2.

__ M. S. Lozier, S. F. Gary, and C. W. Böning, 2009: Interior pathways of the North Atlantic meridional overturning circulation. Nature, 459, 243-247, https://doi.org/10.1038/ nature 07979.

Brodeau, L., B. Barnier, A.-M. Treguier, T. Penduff, and S. Gulev, 2010: An ERA40-based atmospheric forcing for global ocean circulation models. Ocean Modell., 31, 88-104, https://doi.org/ 10.1016/j.ocemod.2009.10.005.

Buckley, M. W., D. Ferreira, J.-M. Campin, J. Marshall, and R. Tulloch, 2012: On the relationship between decadal buoyancy anomalies and variability of the Atlantic meridional overturning circulation. J. Climate, 25, 8009-8030, https:// doi.org/10.1175/JCLI-D-11-00505.1.

Cabanes, C., T. Lee, and L.-L. Fu, 2008: Mechanisms of interannual variations of the meridional overturning circulation of the North Atlantic Ocean. J. Phys. Oceanogr., 38, 467-480, https:// doi.org/10.1175/2007JPO3726.1.

Close, S., T. Penduff, S. Speich, and J.-M. Molines, 2020: A means of estimating the intrinsic and atmospherically forced contributions to sea surface height variability applied to altimetric observations. Prog. Oceanogr., 184, 102314, https://doi.org/ 10.1016/j.pocean.2020.102314.
Czaja, A., and J. Marshall, 2001: Observations of atmosphereocean coupling in the North Atlantic. Quart. J. Roy. Meteor. Soc., 127, 1893-1916, https://doi.org/10.1002/ qj.49712757603.

Danabasoglu, G., and Coauthors, 2014: North Atlantic simulations in Coordinated Ocean-Ice Reference Experiments phase II (CORE-II). Part I: Mean states. Ocean Modell., 73, 76-107, https://doi.org/10.1016/j.ocemod.2013.10.005.

_ - and Coauthors, 2016: North Atlantic simulations in Coordinated Ocean-Ice Reference Experiments phase II (CORE-II). Part II: Inter-annual to decadal variability. Ocean Modell., 97, 65-90, https://doi.org/10.1016/j.ocemod.2015.11.007.

Deremble, B., N. Wienders, and W. Dewar, 2013: CheapAML: A simple, atmospheric boundary layer model for use in oceanonly model calculations. Mon. Wea. Rev., 141, 809-821, https:// doi.org/10.1175/MWR-D-11-00254.1.

Deshayes, J., and C. Frankignoul, 2005: Spectral characteristics of the response of the meridional overturning circulation to deep-water formation. J. Phys. Oceanogr., 35, 1813-1825, https://doi.org/10.1175/JPO2793.1.

- , and 2008: Simulated variability of the circulation in the North Atlantic from 1953 to 2003. J. Climate, 21, 4919-4933, https://doi.org/10.1175/2008JCLI1882.1.

Dussin, R., B. Barnier, L. Brodeau, and J. Molines, 2016: The making of the Drakkar Forcing Set DFS5. DRAKKAR/ MyOcean Rep. 01-04, 16 pp.

Eden, C., and T. Jung, 2001: North Atlantic interdecadal variability: Oceanic response to the North Atlantic Oscillation (18651997). J. Climate, 14, 676-691, https://doi.org/10.1175/1520-0442 (2001) $014<0676$ :NAIVOR $>2.0 . \mathrm{CO} ; 2$.

_ , and J. Willebrand, 2001: Mechanism of interannual to decadal variability of the North Atlantic circulation. J. Climate, 14, 2266-2280, https://doi.org/10.1175/1520-0442(2001)014<2266: MOITDV $>2.0 . C O ; 2$.

Fairall, C., E. F. Bradley, J. Hare, A. Grachev, and J. Edson, 2003: Bulk parameterization of air-sea fluxes: Updates and verification for the COARE algorithm. J. Climate, 16, 571-591, https:// doi.org/10.1175/1520-0442(2003)016<0571:BPOASF >2.0.CO;2.

Frajka-Williams, E., S. Cunningham, H. Bryden, and B. King, 2011: Variability of Antarctic bottom water at $24.5^{\circ} \mathrm{N}$ in the Atlantic. J. Geophys. Res., 116, C11026, https://doi.org/ 10.1029/2011JC007168.

Gastineau, G., and C. Frankignoul, 2012: Cold-season atmospheric response to the natural variability of the Atlantic meridional overturning circulation. Climate Dyn., 39, 37-57, https:// doi.org/10.1007/s00382-011-1109-y.

Goldenberg, S. B., C. W. Landsea, A. M. Mestas-Nuñez, and W. M. Gray, 2001: The recent increase in Atlantic hurricane activity: Causes and implications. Science, 293, 474-479, https://doi.org/ 10.1126/science. 1060040.

Grégorio, S., T. Penduff, G. Sérazin, J.-M. Molines, B. Barnier, and J. Hirschi, 2015: Intrinsic variability of the Atlantic meridional overturning circulation at interannual-to-multidecadal time scales. J. Phys. Oceanogr., 45, 1929-1946, https://doi.org/ 10.1175/JPO-D-14-0163.1.

Häkkinen, S., 2001: Variability in sea surface height: A qualitative measure for the meridional overturning in the North Atlantic. J. Geophys. Res., 106, 13 837-13 848, https://doi.org/10.1029/ 1999JC000155.

Hallam, S., R. Marsh, S. A. Josey, P. Hyder, B. Moat, and J. J.-M. Hirschi, 2019: Ocean precursors to the extreme Atlantic 2017 hurricane season. Nat. Commun., 10, 896, https://doi.org/ 10.1038/s41467-019-08496-4. 
Hirschi, J., and J. Marotzke, 2007: Reconstructing the meridional overturning circulation from boundary densities and the zonal wind stress. J. Phys. Oceanogr., 37, 743-763, https://doi.org/ 10.1175/JPO3019.1.

_- A. T. Blaker, B. Sinha, A. C. Coward, B. A. De Cuevas, S. G. Alderson, and G. Madec, 2013: Chaotic variability of the meridional overturning circulation on subannual to interannual timescales. Ocean Sci., 9, 805-823, https://doi.org/ 10.5194/os-9-805-2013.

Hodson, D. L., and R. T. Sutton, 2012: The impact of resolution on the adjustment and decadal variability of the Atlantic meridional overturning circulation in a coupled climate model. Climate Dyn., 39, 3057-3073, https://doi.org/10.1007/s00382012-1309-0.

Jamet, Q., T. Huck, O. Arzel, J.-M. Campin, and A. Colin de Verdière, 2016: Oceanic control of multidecadal variability in an idealized coupled GCM. Climate Dyn., 46, 3079-3095, https://doi.org/10.1007/s00382-015-2754-3.

— W. W. Dewar, N. Wienders, and B. Deremble, 2019a: Fast warming of the surface ocean under a climatological scenario. Geophys. Res. Lett., 46, 3871-3879, https://doi.org/10.1029/ 2019GL082336.

,,--- , and $\longrightarrow, 2019 \mathrm{~b}$ : Spatio-temporal patterns of chaos in the Atlantic overturning circulation. Geophys. Res. Lett., 46, 7509-7517, https://doi.org/10.1029/2019GL082552.

Johnson, H. L., and D. P. Marshall, 2002: A theory for the surface Atlantic response to thermohaline variability. J. Phys. Oceanogr., 32, 1121-1132, https://doi.org/10.1175/1520-0485(2002)032<1121: ATFTSA $>2.0 . \mathrm{CO} ; 2$.

Kawase, M., 1987: Establishment of deep ocean circulation driven by deep-water production. J. Phys. Oceanogr., 17, 2294-2317, https://doi.org/10.1175/1520-0485(1987)017<2294:EODOCD> 2.0.CO;2.

Kerr, R. A., 2000: A North Atlantic climate pacemaker for the centuries. Science, 288, 1984-1985, https://doi.org/10.1126/ science.288.5473.1984.

Knight, J. R., R. J. Allan, C. K. Folland, M. Vellinga, and M. E. Mann, 2005: A signature of persistent natural thermohaline circulation cycles in observed climate. Geophys. Res. Lett., 32, L20708, https://doi.org/10.1029/2005GL024233.

Kushnir, Y., 1994: Interdecadal variations in North Atlantic sea surface temperature and associated atmospheric conditions. J. Climate, 7, 141-157, https://doi.org/10.1175/1520-0442(1994) 007<0141:IVINAS $>2.0 . \mathrm{CO} ; 2$.

Large, W. G., and S. G. Yeager, 2004: Diurnal to decadal global forcing for ocean and sea-ice models: The data sets and flux climatologies. NCAR Tech. Note NCAR/TN-460+STR, 105 pp., https://doi.org/10.5065/D6KK98Q6.

Leroux, S., T. Penduff, L. Bessières, J.-M. Molines, J.-M. Brankart, G. Sérazin, B. Barnier, and L. Terray, 2018: Intrinsic and atmospherically forced variability of the AMOC: Insights from a large-ensemble ocean hindcast. J. Climate, 31, 1183-1203, https://doi.org/10.1175/JCLI-D17-0168.1.

Levitus, S., and Coauthors, 1998: Introduction. Vol. 1, World Ocean Database 1998, NOAA Atlas NESDIS 18, 346 pp.

Lozier, M. S., 2010: Deconstructing the conveyor belt Science, 328, 1507-1511, https://doi.org/10.1126/science. 1189250 .

, and Coauthors, 2017: Overturning in the Subpolar North Atlantic Program: A new international ocean observing system. Bull. Amer. Meteor. Soc., 98, 737-752, https://doi.org/ 10.1175/BAMS-D-16-0057.1.
- and Coauthors, 2019: A sea change in our view of overturning in the subpolar North Atlantic. Science, 363, 516-521, https:// doi.org/10.1126/science.aau6592.

Marshall, J., A. Adcroft, C. Hill, L. Perelman, and C. Heisey, 1997: A finite-volume, incompressible Navier Stokes model for studies of the ocean on parallel computers. J. Geophys. Res., 102, 5753-5766, https://doi.org/10.1029/96JC02775.

McCarthy, G. D., and Coauthors, 2015a: Measuring the Atlantic meridional overturning circulation at $26^{\circ}$ N. Prog. Oceanogr., 130, 91-111, https://doi.org/10.1016/j.pocean.2014.10.006.

I. D. Haigh, J. J.-M. Hirschi, J. P. Grist, and D. A. Smeed, 2015b: Ocean impact on decadal Atlantic climate variability revealed by sea-level observations. Nature, 521, 508-510, https://doi.org/10.1038/nature14491.

Menary, M. B., L. Hermanson, and N. J. Dunstone, 2016: The impact of Labrador Sea temperature and salinity variability on density and the subpolar amoc in a decadal prediction system. Geophys. Res. Lett., 43, 12 217-12 227, https://doi.org/10.1002/ 2016GL070906.

Molines, J., B. Barnier, T. Penduff, A. Treguier, and J. Le Sommer, 2014: ORCA12. L46 climatological and interannual simulations forced with DFS4.4: GJM02 and MJM88. Drakkar Group Experiment Rep. Tech. Rep., GDRI-DRAKKAR2014-03-19, 50 pp., http://www.drakkar-ocean.eu/publications/ reports/orca12_reference_experiments_2014.

Muir, L. C., and A. V. Fedorov, 2017: Evidence of the AMOC interdecadal mode related to westward propagation of temperature anomalies in CMIP5 models. Climate Dyn., 48, 15171535, https://doi.org/10.1007/s00382-016-3157-9.

Reintges, A., M. Latif, and W. Park, 2017: Sub-decadal North Atlantic oscillation variability in observations and the Kiel climate model. Climate Dyn., 48, 3475-3487, https://doi.org/ 10.1007/s00382-016-3279-0.

Roberts, C., and Coauthors, 2013: Atmosphere drives recent interannual variability of the Atlantic meridional overturning circulation at $26.5^{\circ} \mathrm{N}$. Geophys. Res. Lett., 40, 5164-5170, https://doi.org/10.1002/grl.50930.

Schlesinger, M. E., and N. Ramankutty, 1994: An oscillation in the global climate system of period 65-70 years. Nature, $\mathbf{3 6 7}, 723$ 726, https://doi.org/10.1038/367723a0.

Schott, F. A., R. Zantopp, L. Stramma, M. Dengler, J. Fischer, and M. Wibaux, 2004: Circulation and deep-water export at the western exit of the subpolar North Atlantic. J. Phys. Oceanogr., 34, 817-843, https://doi.org/10.1175/1520-0485(2004)034<0817: CADEAT $>2.0 . \mathrm{CO} ; 2$

Send, U., M. Lankhorst, and T. Kanzow, 2011: Observation of decadal change in the Atlantic meridional overturning circulation using 10 years of continuous transport data. Geophys. Res. Lett., 38, L24606, https://doi.org/10.1029/2011GL049801.

Smeed, D., and Coauthors, 2014: Observed decline of the Atlantic meridional overturning circulation 2004-2012. Ocean Sci., 10, 29-38, https://doi.org/10.5194/os-10-29-2014.

— , and Coauthors, 2018: The North Atlantic Ocean is in a state of reduced overturning. Geophys. Res. Lett., 45, 1527-1533, https://doi.org/10.1002/2017GL076350.

Spall, M. A., 1996a: Dynamics of the Gulf Stream/deep western boundary current crossover. Part I: Entrainment and recirculation. J. Phys. Oceanogr., 26, 2152-2168, https://doi.org/ 10.1175/1520-0485(1996)026<2152:DOTGSW>2.0.CO;2. 1996b: Dynamics of the Gulf Stream/deep western boundary current crossover. Part II: Low-frequency internal oscillations. J. Phys. Oceanogr., 26, 2169-2182, https://doi.org/10.1175/ 1520-0485(1996)026<2169:DOTGSW>2.0.CO;2. 
Sutton, R. T., and B. Dong, 2012: Atlantic Ocean influence on a shift in European climate in the 1990s. Nat. Geosci., 5, 788 792, https://doi.org/10.1038/ngeo1595.

Tulloch, R., and J. Marshall, 2012: Exploring mechanisms of variability and predictability of Atlantic meridional overturning circulation in two coupled climate models. J. Climate, 25, 4067-4080, https://doi.org/10.1175/JCLI-D-11-00460.1.

Wunsch, C., 2013: Covariances and linear predictability of the Atlantic Ocean. Deep-Sea Res. II, 85, 228-243, https://doi.org/ 10.1016/j.dsr2.2012.07.015.

, and P. Heimbach, 2013: Two decades of the Atlantic meridional overturning circulation: Anatomy, variations, extremes, prediction, and overcoming its limitations. J. Climate, 26, 7167-7186, https://doi.org/10.1175/JCLI-D-12-00478.1.

Zhang, R., 2008: Coherent surface-subsurface fingerprint of the Atlantic meridional overturning circulation. Geophys. Res. Lett., 35, L20705, https://doi.org/10.1029/2008GL035463.

2010: Latitudinal dependence of Atlantic meridional overturning circulation (AMOC) variations. Geophys. Res. Lett., 37, L16703, https://doi.org/10.1029/2010GL044474.
_ 2017: On the persistence and coherence of subpolar sea surface temperature and salinity anomalies associated with the Atlantic multidecadal variability. Geophys. Res. Lett., 44, 7865-7875, https://doi.org/10.1002/2017GL074342.

__ , and T. L. Delworth, 2006: Impact of Atlantic multidecadal oscillations on India/Sahel rainfall and Atlantic hurricanes. Geophys. Res. Lett., 33, L17712, https://doi.org/10.1029/ 2006 GL026267.

_ - and G. K. Vallis, 2007: The role of bottom vortex stretching on the path of the North Atlantic western boundary current and on the northern recirculation gyre. J. Phys. Oceanogr., 37, 2053-2080, https://doi.org/10.1175/JPO3102.1.

Zhao, J., and W. Johns, 2014: Wind-forced interannual variability of the Atlantic meridional overturning circulation at $26.5^{\circ} \mathrm{N}$. J. Geophys. Res. Oceans, 119, 2403-2419, https://doi.org/ 10.1002/2013JC009407.

Zou, S., and M. S. Lozier, 2016: Breaking the linkage between Labrador Sea Water production and its advective export to the subtropical gyre. J. Phys. Oceanogr., 46, 2169-2182, https:// doi.org/10.1175/JPO-D-15-0210.1. 